\title{
Source current harmonic mitigation of distorted voltage source by using shunt active power filter
}

\author{
Muhammad Ossama Mahmoud ${ }^{1}$, Wael Mamdouh², Hamdy Khalil ${ }^{3}$ \\ 1,3 Department of Electrical power and machines, Faculty of Engineering, Ain-Shams University, Egypt \\ ${ }^{2}$ Electrical Engineering Department, Egyptian Academy for Engineering and Advanced Technology, EAE\&AT, Egypt
}

\begin{tabular}{l} 
Article Info \\
\hline Article history: \\
Received Dec 7, 2019 \\
Revised Mar 2, 2020 \\
Accepted Mar 9, 2020 \\
\hline Keywords: \\
Four wire shunt active power filter \\
Matlab-Simulink \\
Non-ideal source voltage \\
Non-linear load \\
phase locked loop \\
P-Q theory \\
THD \\
Unbalanced load
\end{tabular}

Unbalanced load

\begin{abstract}
In this paper, three-phase, four-wire shunt active power filter (SAPF) is utilized to mitigate system harmonics of distorted voltage source for unbalanced and nonlinear loads. Basically, the source voltage should be pure sinusoidal waveform to get a good mitigation of source current harmonics. In this under study system, the source voltage is assumed to be harmonic distortion non-sinusoidal voltage source. The phase locked loop (PLL) control circuit is wielded for extracting the fundamental component of the distorted source voltage to use it as an input signal to the SAPF control. Another input signal to the SAPF is the distorted load current. The SAPF control system uses (p-q) theory to calculate the optimum instantaneous current to be injected by the SAPF to mitigate the source current harmonics even the source voltage is harmonic distorted. MATLAB/SIMULINK software package is utilized to simulate the system under study. The effect of SAPF is tested when it's used with and without the PLL control circuit. The simulation results show that, the THD of source current when using the PLL control circuit is improved to comply with the harmonic limits given in the IEEE 519-1992 and IEC 61000-4-7 standards.
\end{abstract}

Copyright (c) 2020 Institute of Advanced Engineering and Science. All rights reserved.

\section{Corresponding Author:}

Muhammad Ossama Mahmoud, Department of Electrical Power and Machines, Faculty of Engineering, Ain-Shams University, Abbasia, Cairo, Egypt.

Email: eng_muhammad100@yahoo.com

\section{INTRODUCTION}

The Power quality is a trend and has a great concern because of using non-linear loads in wide range which is connected to electrical systems. Power electronics controlled component and non-linear load electronic devices in power system create significant deterioration in distribution networks, which lead to rise of voltage and current waveform distortion named harmonics. The non-linear loads draw distorted non-sinusoidal currents from the grid and allotting them throughout the system. This lead to a lot of power quality problems existing in the electrical system grid. Hence, it is necessary to find out solutions to mitigate power system harmonics [1-7]. Some of these solutions are using passive, active and hybrid filters [8-12]. SAPF provides a good solution that reduces the harmonic components and compensates the needed reactive power in three phase three wire and three phase four wire systems. SAPF is designed to be controlled by many control features to be able to compensate harmonic currents, load reactive power and unbalancing neutral currents in power supply. SAPF delivers equal but opposite harmonics current to each phase of the supply system at so called point of common coupling (PCC). A pure sinusoidal source voltage input signal is must and essentially required for SAPF to give high performance of harmonic elimination. In case of distorted voltage source, the SAPF cannot be used alone, but also should be used with series active power filter to eliminate the source voltage harmonic first. After filtering the source voltage harmonics by the series 
active power filter, the voltage at PCC becomes pure sinusoidal and then use this pure sinusoidal as an input source voltage signal to SAPF. This study uses the PLL technique instead of using series active power filter in case of distorted voltage source. The PLL technique is used to extract only the source voltage fundamental component from the distorted source voltage waveform and then deliver this pure source voltage signal as an input signal to the SAPF control scheme, so no need to use additional series active power filter [13-18].

\section{SYSTEM ARCHITECTURE}

The system layout scheme for the system under study consists of electrical power supply, unbalanced nonlinear load, and three phase four wire SAPF based on two dc capacitors is shown in Figure 1. The SAPF is basically a three phase voltage source inverter (VSI) with two capacitors on the dc link. The return neutral path is derived from the center point of two similar capacitors. The zero-sequence component is founded because of the unbalanced load and passing through the neutral. The SAPF inverter is connected to the PCC through an interface coupling inductor. The SAPF acts as a controlled current source delivering the load harmonic currents to the PCC. Consequently, the current absorbed from the grid at the PCC will be pure sinusoidal waveform. Using an (IGBT) transistor, that work as voltage source inverter as a power quality compensation device to generate the switching pulse signal.

This paper uses p-q theory as a control method for SAPF [19, 20]. It is basically based on instantaneous values of three phase source voltage and three phase load current to get active and reactive power required to be compensated even with or without neutral wire. P-Q theory is applicable and has a wide range of use. Three instantaneous powers needed to be defined, first is zero-sequence power p0, second is active power $\mathrm{p}$ and third is reactive power $\mathrm{q}$.

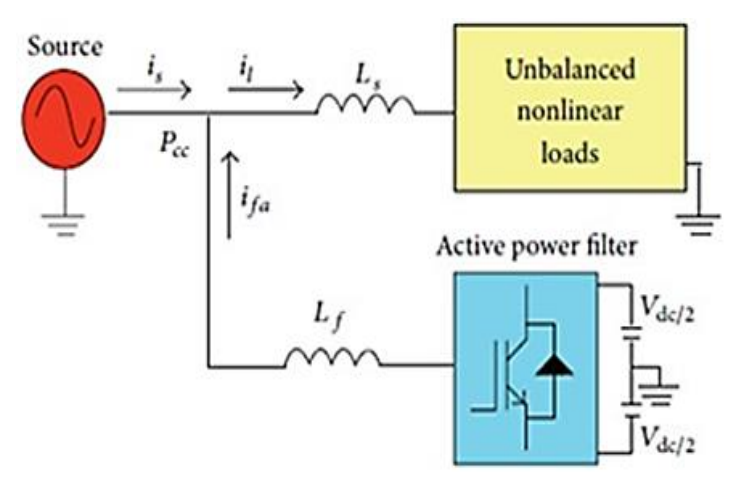

Figure1. Configuration of the 3 phase 4 wire-SAPF

The calculations of these instantaneous power components are as follow:

$$
\begin{aligned}
& {\left[\begin{array}{l}
v_{0} \\
v_{\alpha} \\
v_{\beta}
\end{array}\right]=\sqrt{\frac{2}{3}}\left[\begin{array}{ccc}
1 / \sqrt{2} & 1 / \sqrt{2} & 1 / \sqrt{2} \\
1 & -1 / 2 & -1 / 2 \\
0 & \sqrt{3} / 2 & -\sqrt{3} / 2
\end{array}\right]\left[\begin{array}{l}
v_{a} \\
v_{b} \\
v_{c}
\end{array}\right]} \\
& {\left[\begin{array}{c}
i_{0} \\
i_{\alpha} \\
i_{\beta}
\end{array}\right]=\sqrt{\frac{2}{3}}\left[\begin{array}{ccc}
1 / \sqrt{2} & 1 / \sqrt{2} & 1 / \sqrt{2} \\
1 & -1 / 2 & -1 / 2 \\
0 & \sqrt{3} / 2 & -\sqrt{3} / 2
\end{array}\right]\left[\begin{array}{l}
i_{a} \\
i_{b} \\
i_{c}
\end{array}\right]} \\
& {\left[\begin{array}{c}
p_{0} \\
p \\
q
\end{array}\right]=\left[\begin{array}{ccc}
v_{0} & 0 & 0 \\
0 & v_{\alpha} & v_{\beta} \\
0 & v_{\beta} & -v_{\alpha}
\end{array}\right]\left[\begin{array}{l}
i_{0} \\
i_{\alpha} \\
i_{\beta}
\end{array}\right]}
\end{aligned}
$$

The VSI is utilized to inject the compensating current into the grid. The gate pulses of the VSI are controlled due to the compensating currents from the SAPF. Hysteresis current controller technique is used to control the (VSI) through the pulse width modulation to make the output current of the inverter track the reference current, the hysteresis current controller depend on two signals, reference current signal and 
output inverter current signal. The control circuit of SAPF is producing the reference current which is compared with the output inverter current. When the output inverter current increases out of the designed limits of hysteresis band controller, the hysteresis band controller switches is turned off and on [21].

\section{MATLAB-SIMULINK MODEL}

Figure 2 displays the MATLAB-SIMULINK model for the system under study [22, 23] which consists of, 3-phase distorted voltage source (5th and 7th harmonic orders are included), PLL control circuit, 3-phase transmission line, 3-phase unbalanced nonlinear load, coupling inductor, 3-phase-4Wire SAPF connected to the system at PCC through a 3-phase circuit breaker which is used to connect or disconnect the SAPF from the system, and measuring devices as shown in Figure 2. The system components are listed in Table 1.

Figure 3 shows the components of the SAPF, which consists of, three phase inverter, compensating current calculations, hysteresis band controller, P-Q calculation control, PI controller and coupling inductor. The SAPF is connected at $0.5 \mathrm{sec}$ by using a circuit breaker, to show the effect of SAPF before and after compensation. The overall simulation time is $1 \mathrm{sec}$. The VSI, inductance and the control scheme, as shown in Figure 3.

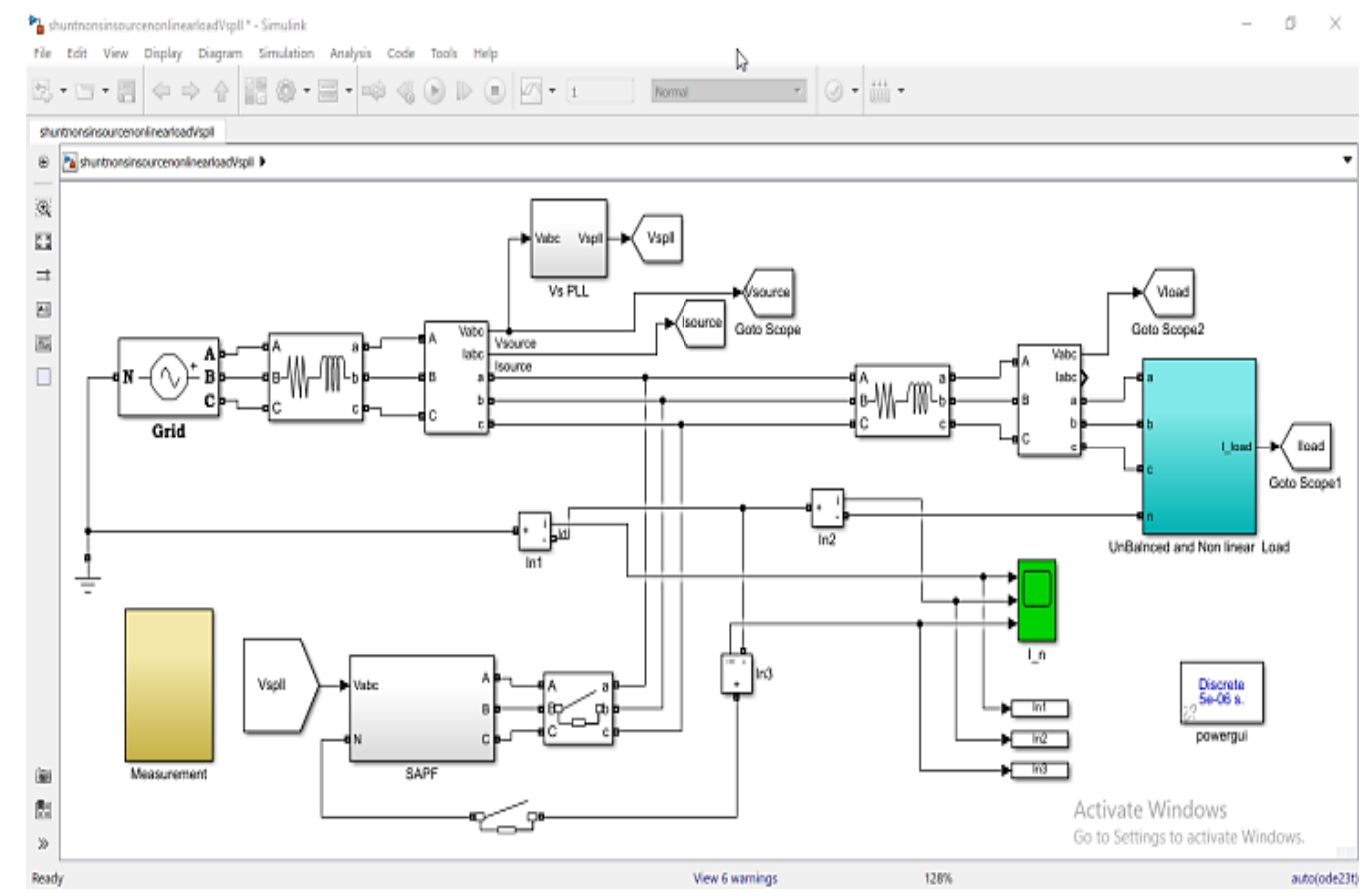

Figure 2. System simulink model

Table.1. System parameters

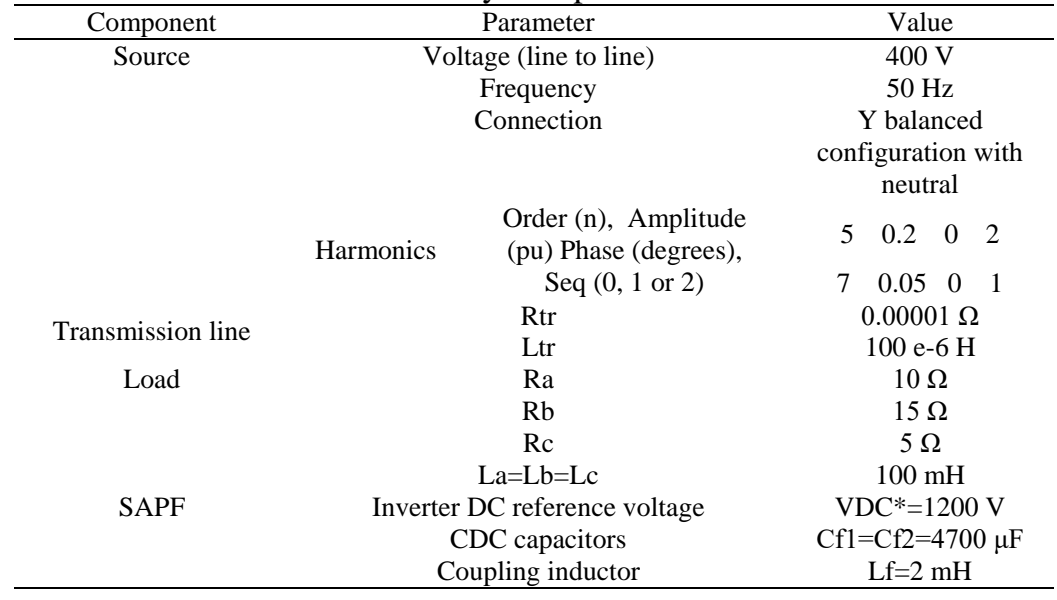

Source current harmonic mitigation of distorted voltage source by using ... (Muhammad Ossama Mahmoud) 


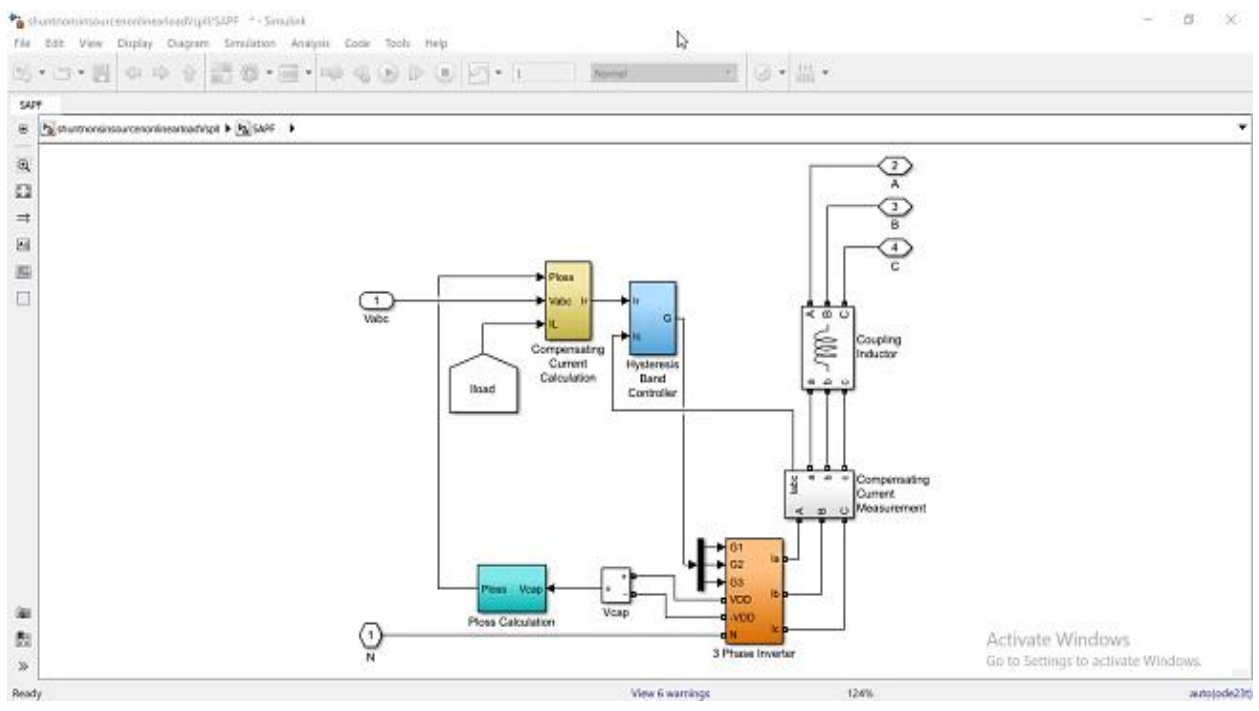

Figure 3. Simulink model of the SAPF

\section{SIMULATION RESULT}

The SAPF control depends on two input signals, (1) source voltage signal (the reference signal), and (2) load current signal. The distortion degree of the source voltage input signal affects badly the elimination of source current harmonics, consequently the compensation current of SAPF, and the THD percentage of source current. Figure 4 shows the PLL control circuit. The input of PLL control cicuit is a 3 -phase source voltage signal, and the outputs are three components, (1) the fundamental frequency, (2) the magnitude of phase voltage, and (3) the phase shift. PLL control circuit extracts only the source voltage fundamental frequency component, and use it as an input signal of the SAPF. When using only a fundamental frequency component of distorted source voltage as a reference input signal, the SAPF will has a great effect on source current harmonic elimination. There are two study cases.

\subsection{Source voltage input signal (without using PLL)}

First case study, using the signal of distorted source voltage (original signal) as an input reference signal to SAPF. Figures 5-11 show source voltage input signal, three phase source current, three phase currents of source, load, and compensation, source neutral current, and FFT analysis of source voltage and source current after and before connecting the SAPF. Figures 5 and 9, show that, the SAPF doesn't have any effect on source voltage distortion. The THD $\%$ of the source voltage input signal is high and equal $20.62 \%$.

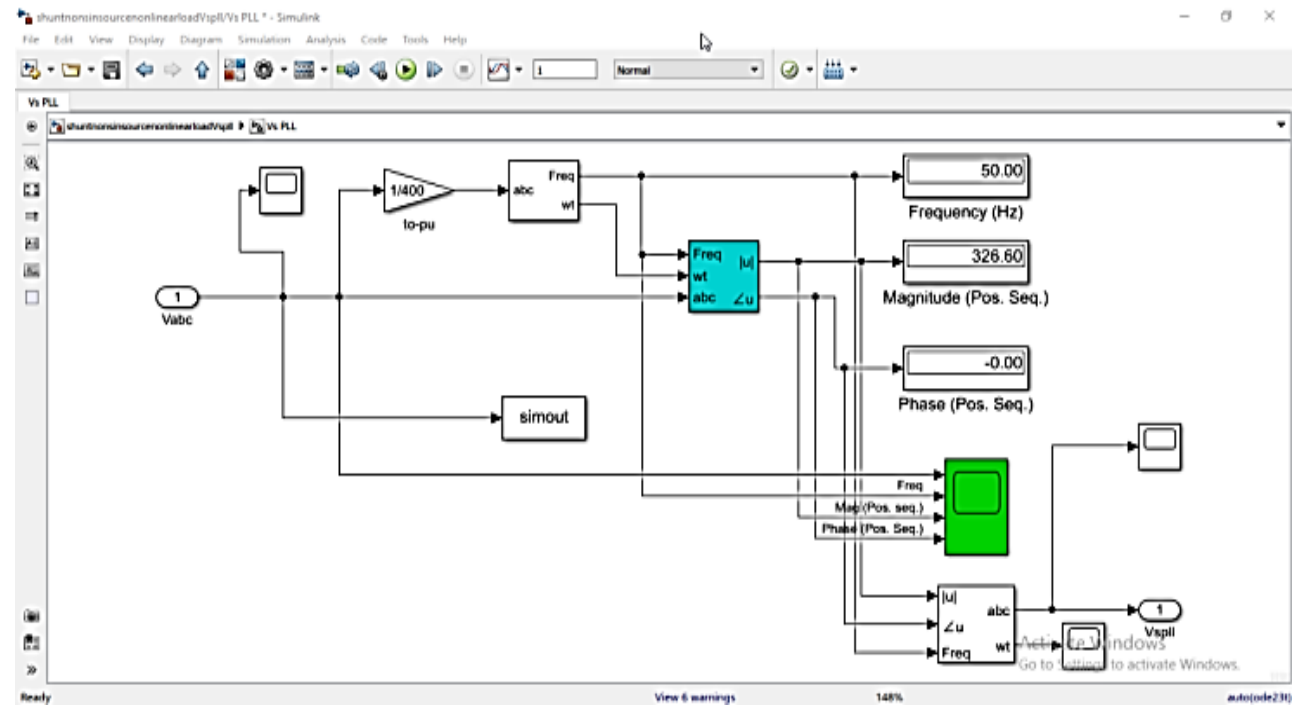

Figure 4. Simulink model of the PLL 


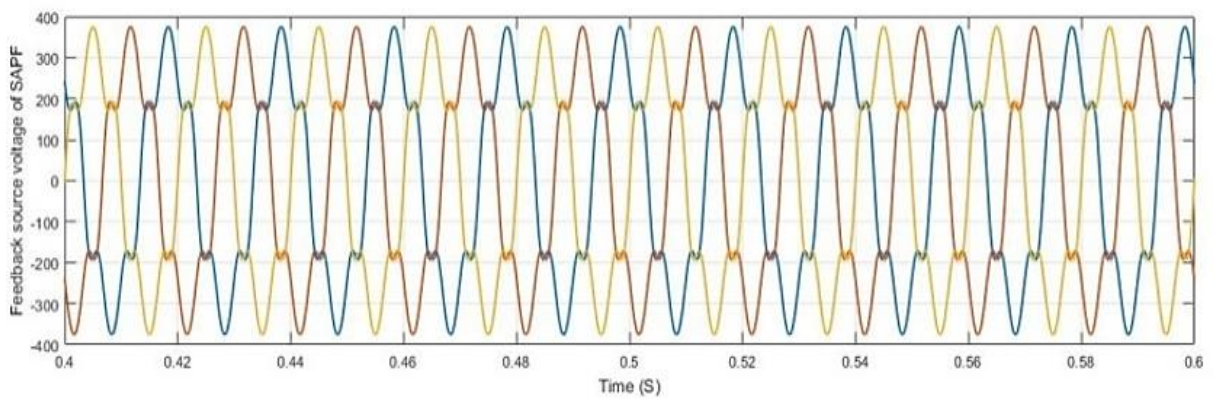

Figure 5. Source voltage input signal of SAPF without using PLL (case A)

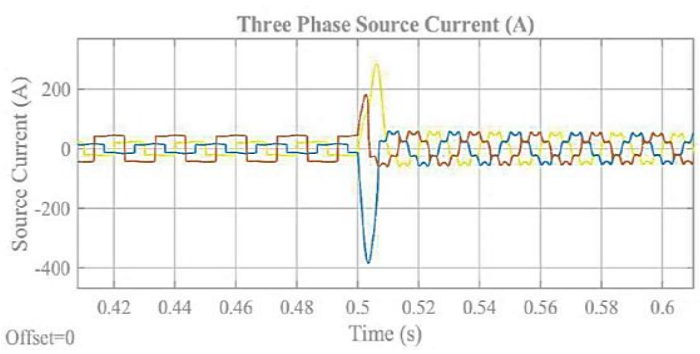

Figure 6. Three phase source current (case A)

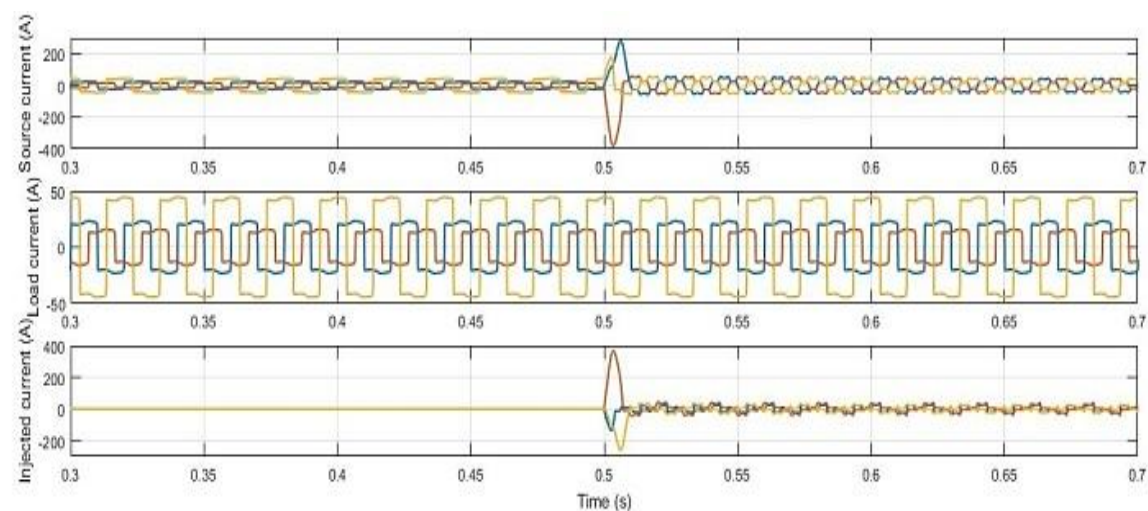

Figure 7. Three phase source current, load current, and compensation current (case A)

As illustrated in Figures 6, 7, 10 and 11, the SAPF has a low effect on source current harmonic elimination. The THD\% of the source current reduced after connecting SAPF but still beyond and out of the standard limits [24-25]. As shown in Figure 8, the neutral source current is eliminated. Table 2 shows the THD\% of source current.
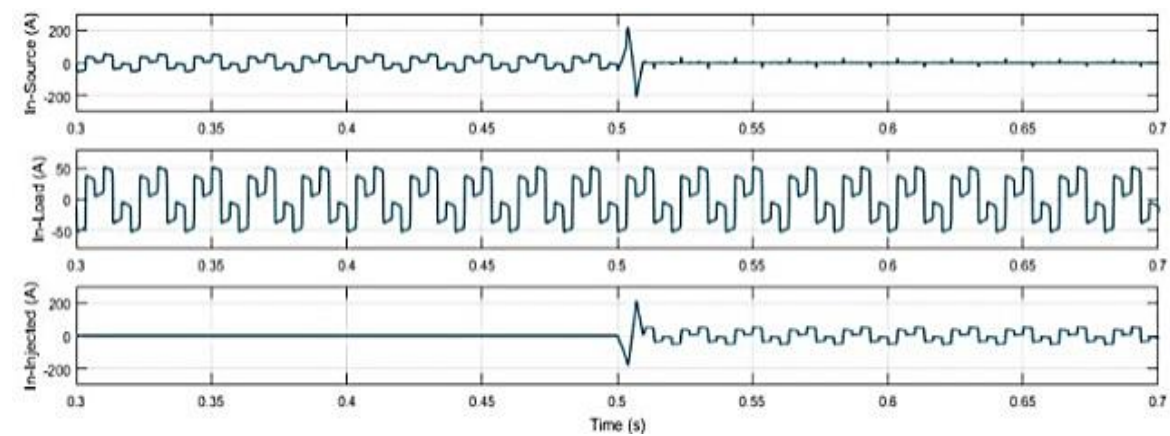

Figure 8. Neutral currents of source, load and compensation of SAPF 

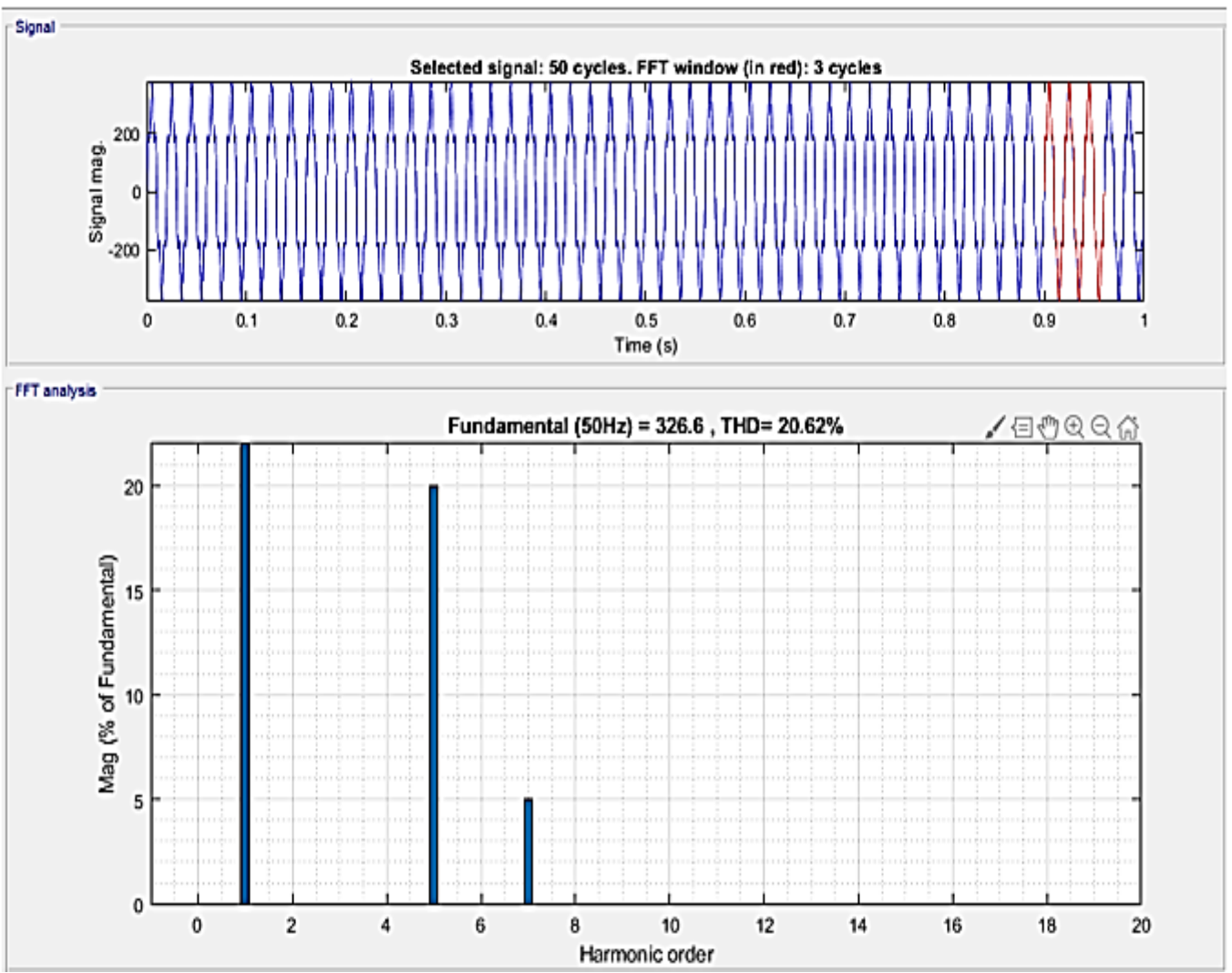

Figure 9. FFT analysis for source voltage input signal without using PLL (case A)
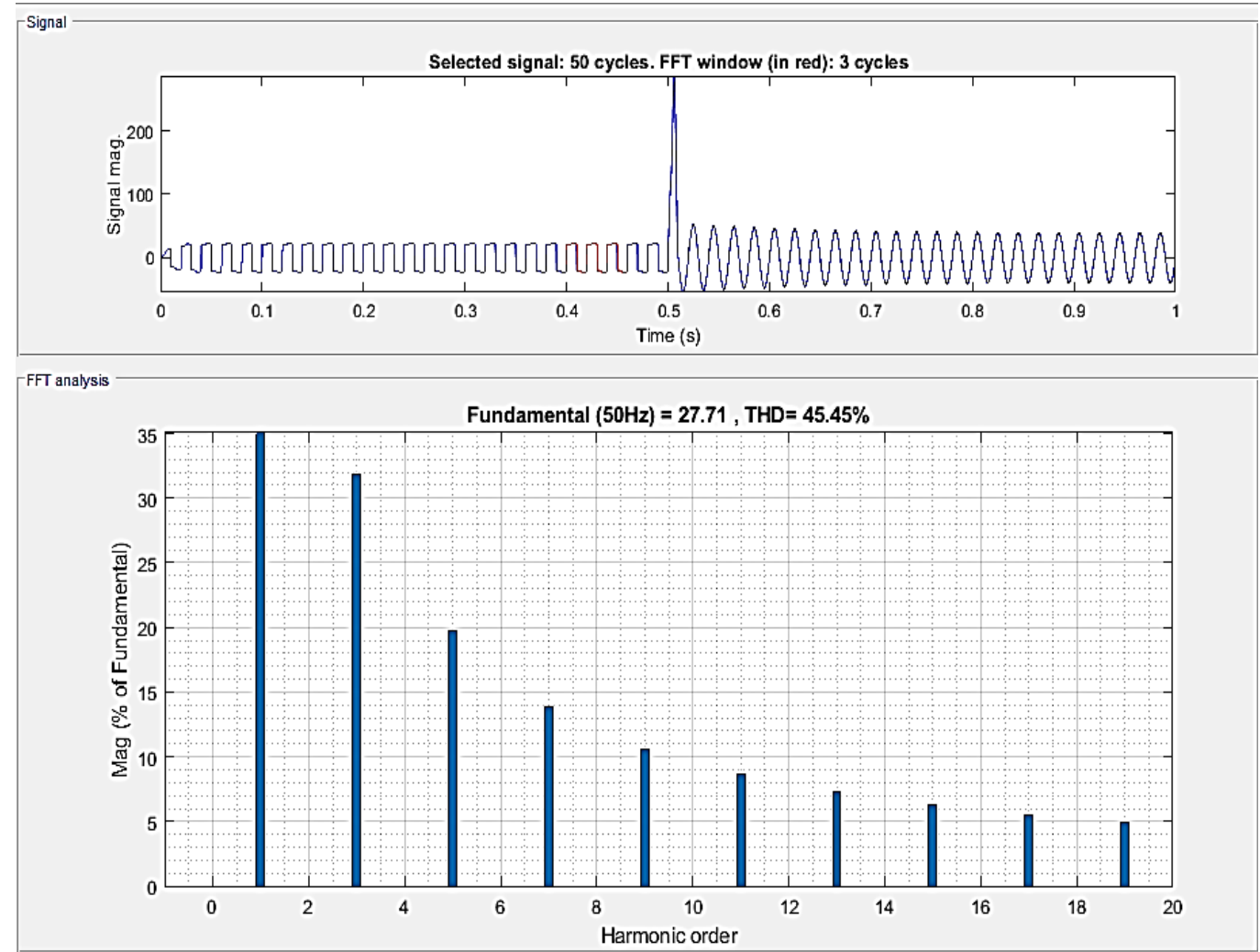

Figure 10. FFT analysis for source current before connecting SAPF (case A) 


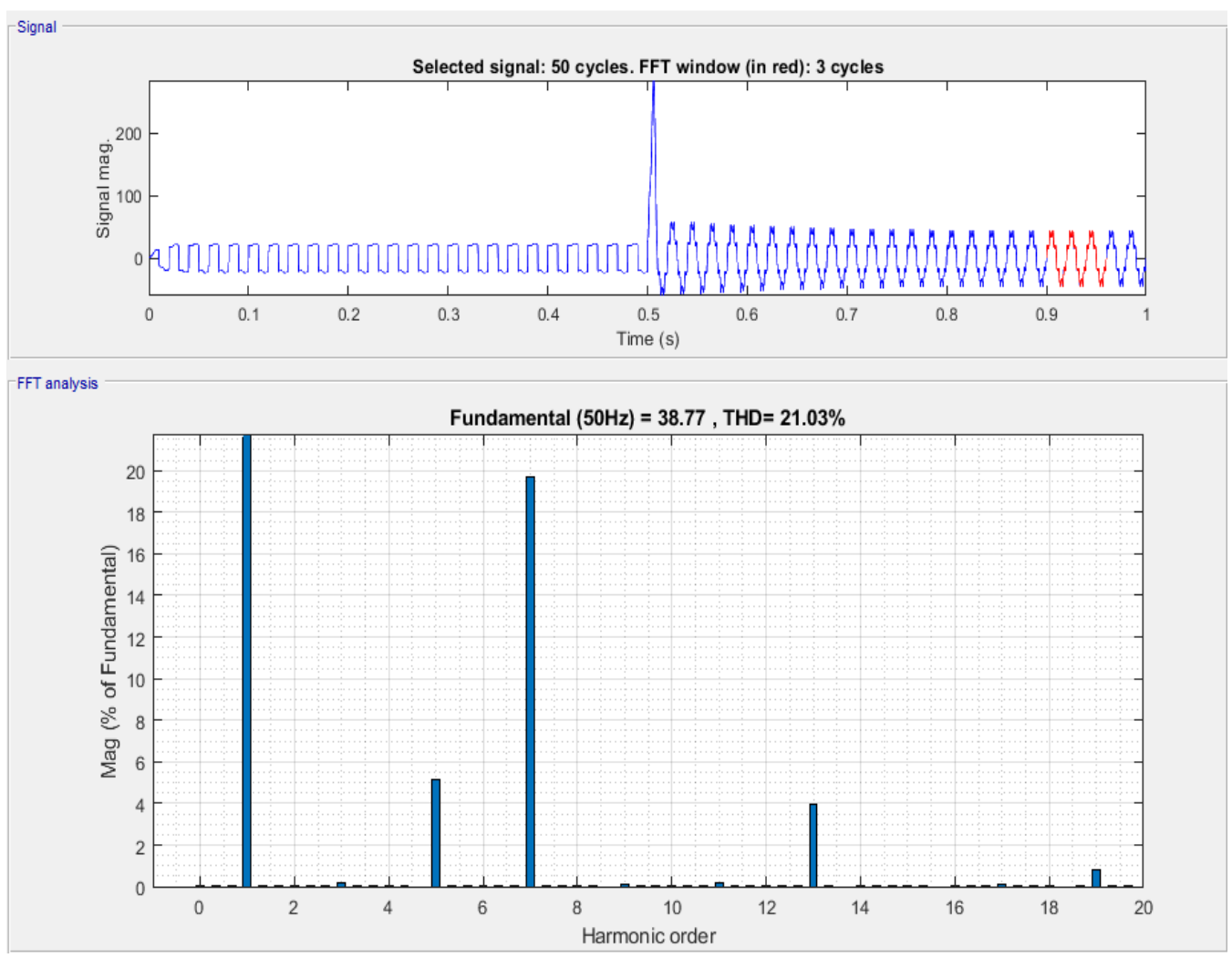

Figure 11. FFT analysis for source current after connecting SAPF (case A)

Table. 2 THD\% of source current (case A)

\begin{tabular}{ccc}
\hline Source current & Source current before connecting SAPF & Source current after connecting SAPF \\
\hline THD $\%$ & 45.45 & 21.03 \\
\hline
\end{tabular}

\subsection{Source voltage input signal (with using PLL)}

Figures 12-16, show that, source voltage input signal, three phase source current, three phase currents of source, load, and compensation waveforms, and FFT analysis of source voltage input signal and source current after connecting SAPF. When using the output of PLL control circuit as reference input signal of SAPF (reference input signal), it is noticed that, (1) the SAPF has a good effect on source current harmonic elimination; (2) the THD\% of source current is within the standard limits because the source voltage input signal become a pure sine wave. Table 3 shows the THD\% of source current. As shown in Tables 4 and 5 , the THD $\%$ of source current under distorted voltage source and nonlinear unbalanced load matches the standard limits.

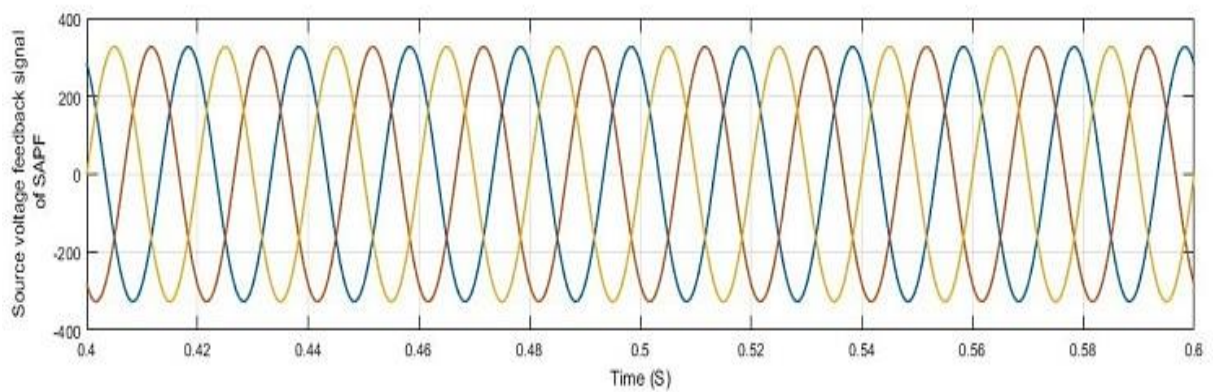

Figure 12. Source voltage input signal of SAPF by using PLL (case B) 


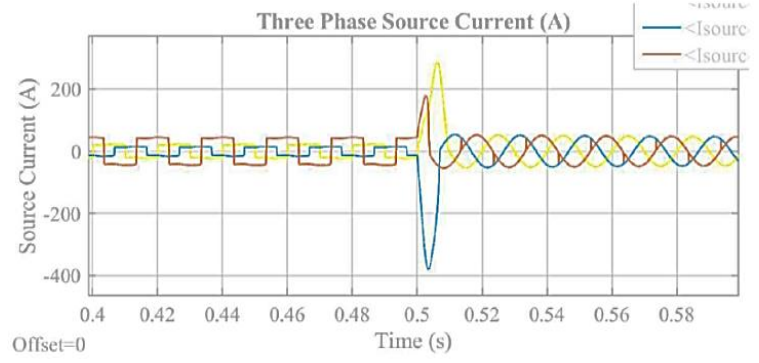

Figure 13. Three phase source current (case B)

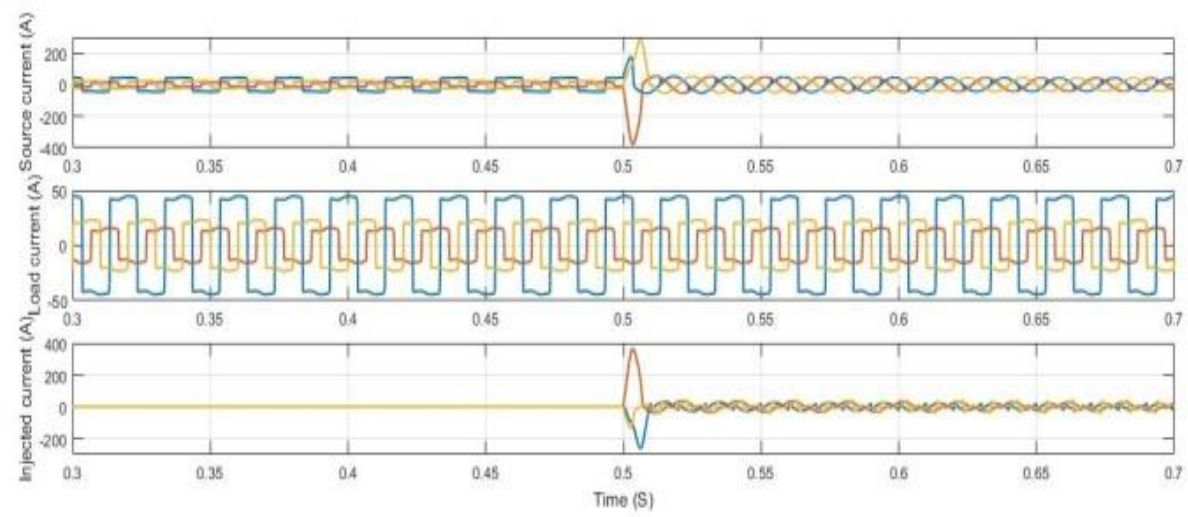

Figure 14. Source current, load current, and compensation current (case B)

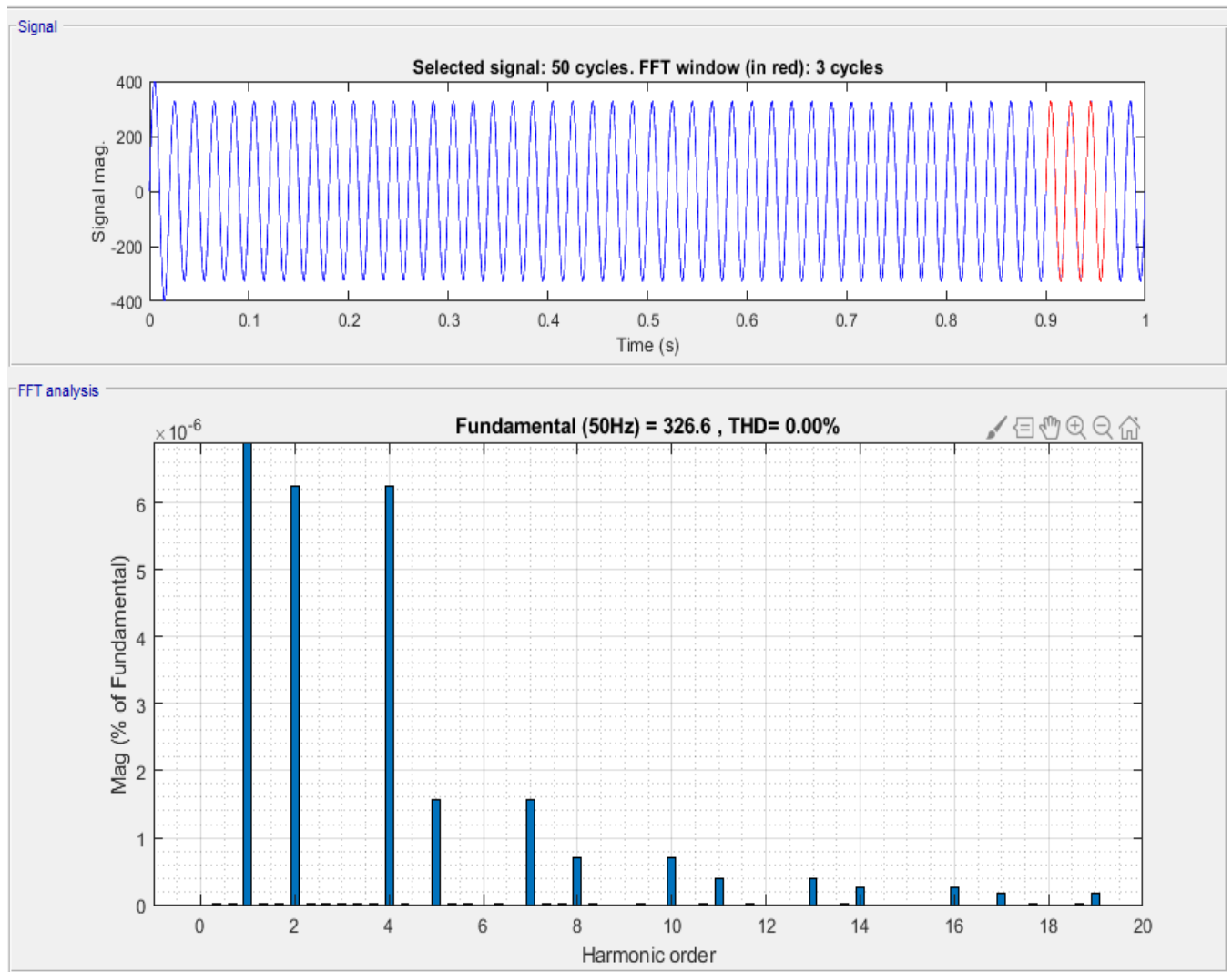

Figure15. FFT analysis for source voltage input signal with PLL (case B) 


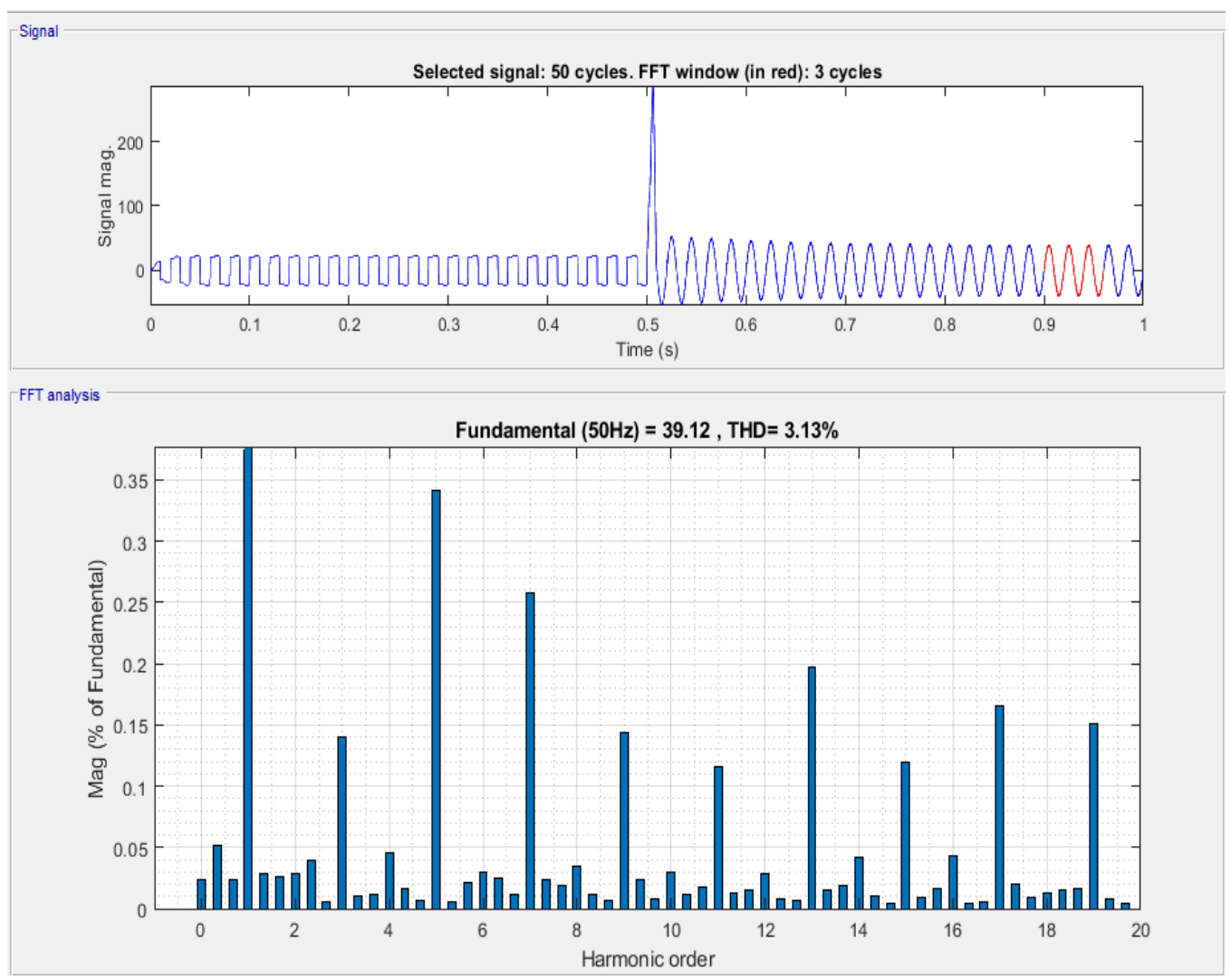

Figure16. FFT analysis for source current after connecting SAPF (case B)

Table 3. THD of source current (case B)

\begin{tabular}{ccc}
\hline Source current & Source current before connecting SAPF & Source current after connecting SAPF \\
\hline THD $\%$ & 45.45 & 3.13 \\
\hline
\end{tabular}

Table 4. THD\% of source voltage input signal

\begin{tabular}{ccc}
\hline Source voltage input signal & Without using PLL & With using PLL \\
\hline THD \% & 20.62 & 0.00
\end{tabular}

Table 5. THD\% of source current

\begin{tabular}{cccc}
\hline Source current & $\begin{array}{c}\text { Source current before } \\
\text { connecting SAPF }\end{array}$ & $\begin{array}{c}\text { Source current after connecting } \\
\text { SAPF without using PLL }\end{array}$ & $\begin{array}{c}\text { Source current after connecting } \\
\text { SAPF with using PLL }\end{array}$ \\
\hline THD\% & 45.45 & 21.03 & 3.13 \\
\hline
\end{tabular}

\section{CONCLUSION}

By using the PLL control circuit with distorted source voltage as the reference input signal to the SAPF, it is noticed that, (1) the SAPF has a great effect on the source current harmonic elimination, (2) the 3-phase, 4Wire SAPF compensate the neutral current effectively, (3) the THD\% of the source current is within the standard limits.

\section{ACKNOWLEDGEMENTS}

I would like to express my deeply gratitude and appreciation to Prof. Dr. Hamdy Saleh Khalil El-Gohary, who choose the topic of the thesis, give all required guidelines, support and assistance during the whole period of preparation of the thesis. Finally, I gratefully acknowledge and thank my parents and wife for their patience, understanding and encouragement during the research period. 


\section{REFERENCES}

[1] S. Rahmani, Ab. Hamadi, and K. Al-Haddad, "A Comprehensive Analysis of Hybrid Active Power filter for Power Quality Enhancement," IECON 2012-38th Annual Conference on IEEE Industrial Electronics Society, Montreal, QC, pp. 6258-6267, 2012.

[2] Bhim Singh, Kamal Al-Haddad, and Ambrish Chandra, Member, "A Review of Active Filters for Power Quality Improvement," in IEEE Transactions on Industrial Electronics, vol. 46, no. 5, pp. 960-971, Oct. 1999.

[3] S. Bhattacharya, D. M. Divan, B. Banerjee, "Active Filter Solutions for Utility Interface," Proceedings of International Conference on Power Electronics, Drives and Energy Systems for Industrial Growth, New Delhi, India, vol. 2, pp. 1078-1084, 1996

[4] Po-Tai Cheng Subhashish Bhattacharya, Deepak M. Divan, "Application of dominant harmonic active filter system with 12 pulse nonlinear loads," in IEEE Transactions on Power Delivery, vol. 14, no. 2, pp. 642-647, Apr. 1999.

[5] C. A. Quinn and N. Mohan, "Active filtering of harmonic currents in three-phase, four-wire systems with threephase and single-phase nonlinear loads," Proceedings Eighth Annual Applied Power Electronics Conference and Exposition, San Diego, CA, USA, pp. 841-846, 1993.

[6] Conor A. Quinn, Ned Mohan, and Harshad Mehta, "A four-wire, current-controlled converter provides harmonic neutralization in three-phase, four-wire systems," [Proceedings] APEC '92 Seventh Annual Applied Power Electronics Conference and Exposition, Boston, MA, USA, pp. 829-836, 1992.

[7] Ravi Samikannu, R. Rohini, V. Sampath Kumar, Vitaliy Mezhuyev, "Design and Development of Shunt Active Filter Using MATLAB for Minimization of Harmonics," International Journal of Engineering \& Technology, vol. 7, no. 3.10, pp 179-183, 2018.

[8] Yonghai Xu, Xiangning Xiao, Hao Liu, and Hong Wang, "Parallel operation of hybrid active power filter with passive power filter or capacitors," 2005 IEEE/PES Transmission \& Distribution Conference \& Exposition: Asia and Pacific, Dalian, pp. 1-6, 2005.

[9] ZHANG Zhang, JIANG HuiLan, ZHANG HuiJian, WANG JingPeng, "Active Power Filter Design and Simulation by Combining LabVIEW and Simulink," 2011 International Conference on Advanced Power System Automation and Protection, Beijing, pp. 1104-1109, 2011.

[10] Amaraja Joshi, Mulla Anwar Mubarak, Aniket Dhmangaonkar, "Design \& Simulation of Shunt Active Power Filter Using P-Q Theory for Power Quality Improvement," International Journal of Industrial Electronics and Electrical Engineering, vol. 4, no. 4, pp. 16-21, Apr. 2016.

[11] D. M. Soomro, S. C. Chong, Z. A. Memon, F. Abbasi, "Investigation and Design of an Active Power Filter for PQ Issue at QUCEST Larkana Campus Using Matlab/Simulink," 2016 IEEE International Conference on Power System Technology (POWERCON), Wollongong, NSW, pp. 1-6, 2016.

[12] Marius Marcu, Florin-Gabriel Popescu, Titu Niculescu, Leon Pana, and Alina Daniela Handra, "Simulation of power active filter using instantaneous reactive power theory," 2014 16th International Conference on Harmonics and Quality of Power (ICHQP), Bucharest, pp. 581-585, 2014.

[13] Naimish Zaveri, Ajitsinh Chudasama, "Control strategies for harmonic mitigation and power factor correction using shunt active filter under various source voltage conditions," International Journal of Electrical Power \& Energy Systems, vol. 42, no. 1, pp. 661-671, Nov. 2012.

[14] IEEE Standard Definitions for the Measurement of Electric Power Quantities Under Sinusoidal, Nonsinusoidal, Balaced, or Unbalanced Conditions, IEEE standard $1459^{\mathrm{TM}}-2010$, IEEE Power and Energy Society, New York, USA, 19 Mar. 2010.

[15] Kishore Kumar Pedapenki, S. P. Gupta, Mukesh Kumar Pathak, "Soft Control Techniques for Shunt Active Power Filter," 2015 IEEE Power, Communication and Information Technology Conference (PCITC), Bhubaneswar, pp. 60-65, 2015.

[16] Dayaratna, L., \& Riley, T., "TMA: Theory and design of phase-locked loops," 2004 IEEE MTT-S International Microwave Symposium Digest (IEEE Cat. No.04CH37535), Fort Worth, TX, USA, pp. 11-11, 2004.

[17] N. Parkalian, M. Robens, C. Grewing, V. Christ, D. Liebau, P. Muralidharan, D. Nielinger, U. Yegin, A. Zambanini and S. van Waasen, "Modeling and Simulation of Digital Phase-Locked Loop in Simulink," 2018 15th International Conference on Synthesis, Modeling, Analysis and Simulation Methods and Applications to Circuit Design (SMACD), Prague, pp. 121-129, 2018.

[18] Abhishek Godave, Pranali Choudhari, and Anita Jadhav, "Comparison and Simulation of Analog and Digital Phase Locked Loop," 2018 9th International Conference on Computing, Communication and Networking Technologies (ICCCNT), Bangalore, pp. 1-4, 2018.

[19] Mohammad Sadegh Karbasforooshan, Mohammad Monfared, "Design and implementation of a single-phase shunt active power filter based on PQ theory for current harmonic compensation in electric distribution networks," IECON 2017 - 43rd Annual Conference of the IEEE Industrial Electronics Society, Beijing, pp. 6389-6394, 2017.

[20] Hirofumi Akagi, Yoshihira Kanazawa, Akira Nabae, "Instantaneous Reactive Power Compensator Comprising Switching Devices without Energy Storage Components," in IEEE Transactions on Industry Applications, vol. 1A-20, no. 3, pp. 625-630, May 1984.

[21] Kale, M., \& Ozdemir, "A novel adaptive hysteresis band current controller for shunt active power filter," Proceedings of 2003 IEEE Conference on Control Applications, 2003. CCA 2003, Istanbul, Turkey, vol. 2, pp. 1118-1123, 2003.

[22] SIMULINK: “The Dynamic System Simulation Software-User’s Guide,” MathWorks Incorporated, Apr. 1993. 
[23] G. Rajpriya, S. Ravi, and Ahmad Mujahid A. Zaidi, "Design and development of Matlab/Simulink based Selective Harmonic Elimination technique for three phase voltage source inverter," 2013 International Conference on Advanced Computing and Communication Systems, Coimbatore, pp. 1-5, 2013.

[24] IEEE, "Recommended Practices and Requirements for Harmonic Control in Electrical Power Systems," in IEEE Std 519-1992, pp. 1-112, 9 Apr. 1993.

[25] Electromagnetic compatibility (EMC)-Part 4-7: Testing and measurement techniques-General guide on harmonics and interharmonics measurements and instrumentation, for power supply systems and equipment connected thereto, IEC standard 61000-4-7, EMC, Oct. 2009

\section{BIOGRAPHIES OF AUTHORS}
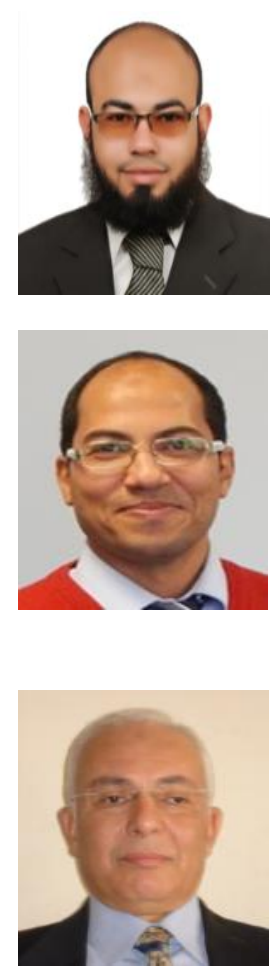

Muhammad Ossama Mahmoud received his B.Sc Electrical Engineering Degree from Department of Electrical power and machines Engineering at AL-Azhar University, Cairo, Egypt and M.Sc Electrical Engineering Degree from Department of Electrical power and machines Engineering at Cairo University, Giza, Egypt. Currently he is a Ph.D researcher at Ain-Shams University, Abbasia, Cairo, Egypt. His research interests in power quality issues. Email: eng_muhammad100@yahoo.com

Dr. Wael Mohamed Mamdouh received his B.Sc. of Electrical Power and Machines Engineering Degree from Department of Electrical Power and Machines Engineering (DEPME) at the Faculty of Engineering, Cairo University (CU), Cairo, Egypt, M.Sc. of Electrical Power and Machines Engineering Degree from DEPME at the Faculty of Engineering, CU, Cairo, Egypt, and Ph.D. of Electrical Power and Machines Engineering Degree from DEPME at the Faculty of Engineering, CU, Cairo, Egypt. . Currently he is working as an Assistant Professor in the Department of Electrical Engineering Department, Egyptian Academy for Engineering and Advanced Technology (EAE\&AT), Cairo, Egypt. His research interests include power electronics, renewable energy, and power system protection. Email: wael@eaeat.edu.eg

Prof. Dr. Hamdy Khalil Elgoharey received his B.Sc. and M.Sc. degrees from Ain-Shams university, Cairo, Egypt in 1967 and 1969 respectively, He received his second M.Sc. and his Ph.D degrees from University of Saskatchewan, Saskatchewan, Canada in 1974 and 1978 respectively. In 1980, He joined The department of Electrical Power and Machines at Ain-Shams University, and in 1992, He became professor of Electrical Power and Machines. Currently He is Professor Emeritus in the Electrical Power and Machines Department, College of Engineering, Ain-Shams University. His research interests include Power electronics and applications to power systems (FACTS), Electric drives and their control, Control of electric machines and power systems, and HVDC/HVDC Light transmission systems and their control. Email: hamdyk@ hotmail.com 